\title{
Research on the Cultivation of College English Skills Based on the Mobile Learning
}

\author{
Xuefang Zhang \\ Zhejiang Yuexiu University, Shaoxing, China \\ Email: 20131050@zyufl.edu.cn
}

How to cite this paper: Zhang, X.F. (2021) Research on the Cultivation of College English Skills Based on the Mobile Learning. Open Access Library Journal, 8: e7473.

https://doi.org/10.4236/oalib.1107473

Received: April 29, 2021

Accepted: June 6, 2021

Published: June 9, 2021

Copyright (C) 2021 by author(s) and Open Access Library Inc.

This work is licensed under the Creative Commons Attribution International License (CC BY 4.0).

http://creativecommons.org/licenses/by/4.0/

\section{(c) (i) Open Access}

\begin{abstract}
At present, the overall situation of College Students' English learning is not optimistic, which is characterized by "Four NOTs": not interested in English learning, not memorizing enough words, not listening to English materials of high levels, and not good at oral expression. As a new way of English learning, Mobile Learning can well meet the needs of students' English learning. It is a beneficial supplement to traditional English education and has a positive impact on the balance of English education resources and the construction of a learning society. Meanwhile, Mobile learning breaks through the constraints of time and space in the traditional teaching mode. Consequently, students can acquire knowledge, communicate and interact with each other anytime, anywhere when they want. In this way, it fully reflects the student's dominant position in the learning process.
\end{abstract}

\section{Subject Areas}

Linguistics

\section{Keywords}

Mobile Learning, College English, Teaching Mode

\section{Introduction}

Language is the need of social communication and social practice, so it has the vitality only in communication. The ultimate goal of learning a foreign language is to communicate in that language. This communicative ability includes the ability to accurately receive and send information. The former includes listening and reading, and the latter includes speaking and writing.

College English teaching needs a system guided by foreign language teaching theory, with English language knowledge, application skills, cross-cultural 
communication and learning strategies as the main contents, and integrates a variety of teaching models. The teaching goal of the course is to cultivate students' comprehensive language abilities, so that they can communicate effectively in English in their future study, work or other social interactions (Wang Shouren, 2009) [1]. At the same time, it can enhance their independent learning and improve cultural literacy, which meets the need of our country's development and international exchanges. Thus, the design of this course should fully consider the requirements of English skills training, and give enough learning hours or course credits to the course. Advanced information technology should be used extensively to construct various computer- and network-based courses so as to provide students with a good language learning environment.

With the development of Internet technology and the increasing maturity of Mobile Learning (M-learning) equipments, M-learning is providing convenient and flexible learning methods for the majority of learners (Cao Chao, 2010) [2]. Mobile APPs, as application softwares loaded on mobile devices, allow English learners to choose the study time freely, conduct interactive exercises anytime and anywhere at their convenience. The rise of M-learning was originated from the widespread acceptance of mobile communication technology by the public, and it also injects new vitality into online education in the Internet age. Mobile communication technology has the following functions on learning: to increase the scope of education, to encourage personalized learning, to provide timely feedback and evaluation, to ensure learning at anytime and anywhere, to improve the effectiveness of the classroom teaching, to establish a new type of student community, to support situational learning and to promote students' communication (Hu Jiasheng \& Chen Jianlin 2013, Received Date: 2015) [3].

\section{The Definition of M-Learning}

In the western countries, M-Learning has received a lot of attention since the "Mobile Education" launched in 2000 by the University of California, Berkeley. After that, the two research projects of the European Union, "From E-Learning to M-Learning" and "MOBI-Learn Action", further promoted the development of M-learning. And at the same time, the United Kingdom has also launched the corresponding projects. These three projects are important for the Mobile Learning. The study of the framework of M-learning is of great significance. At meanwhile, the "Mobile Learning" researches carried out by the University of Birmingham, Stanford University, Ericsson, Nokia and other commercial companies have studied the interactive technology, learning mode, ways and methods to integrate with traditional classroom teaching. The emergence of the new term M-Learning has promoted the development of mobile devices. Some researchers also focus on the feasibility of using mobile devices in practical teaching and learning from the perspective of cognition and teaching.

In China, most of the studies start from the characteristics of Mobile Learning and pay attention to the help of this new learning method for language learning; 
there are also some studies that try to introduce mobile APPs into the classroom and propose new educational models. Scholars such as Xu Tao [4] and Wang Lili [5] applied mobile technology to create an autonomous, and cooperative learning environment in which it can transform students' learning mode and improve classroom teaching effects. Zhu Lin [6] and Chen Huali [7] combined mobile technology with specific subject teaching, giving full play to the advantages of mobile technology, and build an appropriate mixed-teaching environment which provides opportunities for teachers and students to teach and learn anytime and anywhere. Jing Ruili [8] discussed the application characteristics of mobile technology in English learning, especially in English listening and speaking classes. Based on the analysis of the current situation of College English listening and speaking teaching in China, Lan Liwei [9] studied the strategies of using multimedia for college English listening and speaking teaching from the following five aspects-developing good listening and speaking habits, overcoming learning anxiety, improving cross-cultural communication awareness, enhancing listening and speaking skills, and raising teachers' language skills. Through these researches and comparisons, it can be found that with the development of society, M-learning methods can meet the individual needs of students to a greater extent, increase students' interest in learning, and extend learning time.

However, as a brand-new learning method that is being widely used, M-learning does not yet have a clear definition. This is because M-learning involves many elements. Experts and scholars at home and abroad understand and interpret it from different aspects. In general, the definition of M-learning can be illustrated from the perspective of technology and the perspective of learning methods. From a technical point of view, this view is supported by most of the current research literature. Most researchers believe that the basic feature of M-learning is mobility, which is the product of the combination of mobile technology and learning. In this view, M-learning is regarded as learning with the use of mobile devices such as PDAs, laptops, Tablet PCs, iPods, and mobile phones. These devices can be combined with wireless technology to deliver and present learning contents, and enable learners to interact with others.

Defined from the perspective of learning methods, in other studies, researchers have found that M-learning should not only stay at the device level, but also discuss how M-learning can bring about changes in learning methods for learners. Franz Lehner and Holger Nosekahel of the University of Regensburg believe that any service that provides learners with a wide range of digital information and helps learners acquire knowledge at any time and any place belongs to the category of M-learning (2010) [10].

From my eyes, M-learning is a digital learning method by which learners use portable mobile devices at any time and place when and where learning needs to occur. In this way, learners can obtain the most suitable information through mobile communication technology and realize meaningful learning in two-way communication with others. 


\section{The Advantages of M-Learning}

The continuous popularization and application of mobile devices provide effective technical support for M-learning. Generally speaking, mobile technology assisted English learning reflects the following advantages.

\subsection{The Ubiquitous Nature of M-Learning Makes It Possible to Learn Anytime, Anywhere}

Mobile phones, smart phones, and other mobile devices have good portability. Students can carry them and study in any place with their learning needs. Mobile devices carry multimedia learning resources in the form of pictures, texts, audios or videos. These learning resources can create a rich and vivid "ubiquitous” environment for students' English learning. Learners can decide learning time and space freely. And it even can infinitely extend the learning resources under the traditional learning. So learning can be naturally integrated into work, life or other social interactions. In this way, it can create a good learning environment for English learners, so that the learners have ample opportunities to exercise English listening, speaking, reading and writing, build up self-confidence and improve their those four skills.

\subsection{The Timeliness of M-Learning Can Create Real Contextualization}

In the M-learning environment, it can provide learners with the most appropriate knowledge and information at the very time when they need them, regardless of where they are. Therefore, M-learning can also be called just-in-time learning. Learners have learning motivations in different situations and can use mobile devices to learn as they like. If they encounter difficulties, they can query related questions through wireless communication technology and connect to meet the individual learning needs at that time, such as BAIDU or GOOGLE. The purpose of language learning is to properly use language to communicate in different situations. That's why it is necessary to put students in a real communicative environment as much possible as we can, so that students can personally experience the real process of verbal communication. This is the first step in cultivating English communicative competence. Obviously, the timeliness of Mobile Learning can make language learning in specific situations more effective.

\subsection{The Interactivity of M-Learning Can Create a Good Psychological Environment for Students}

The interaction in M-learning is reflected in two aspects. On the one hand, students can obtain rich English learning resources and have a personalized learning experience through convenient and timely human-computer or human-mobile devices interaction. On the other hand, mobile devices can establish a good communicative environment for students, families, and communities in which students' independent learning and collaborative learning are inspired; family education and school education are also connected (Liu Haixia, 2013) [11]. Mo- 
bile devices such as mobile phones, smart phones and other mobile devices are the typical communication devices. SMS and calls are the most frequently used communication methods in our daily life. This provides convenience for the interaction between teachers and students. By this means, students gain knowledge through natural and cordial communication, eliminate emotional barriers, overcome fears and low self-esteem, and prepare for the classroom learning ultimately. Additionally, the interaction among students can increase mutual understanding and lay a solid foundation for cooperative learning in and out of class.

\subsection{The Multimedia Feature of M-Learning Is Conducive to Cultivating Cross-Cultural Communication Skills}

Foreign language learning is inseparable from the penetration of culture (Wang Shouren, 2009) [1]. It is necessary to combine language learning with culture. Most mobile devices support multiple media types such as text, audio, video, and animation, which can provide vivid and realistic teaching materials to learners. Students can use wireless network connections to obtain the relevant learning resources at any time like multimedia materials, especially video and audio clips. These pre-designed clips that integrate language and culture can allow students to learn English in a cultural context, which can enable students to better understand cultural differences and improve the appropriateness of language expression. Appropriateness in a language not only saves time for classroom teaching, but also realizes the integration of language learning and culture.

\subsection{Personalization of M-Learning Facilitates Teaching in Accordance with Students' Aptitude}

The premise of teaching in accordance with students' aptitude is that teachers must fully know the personality of each student, which is very difficult to achieve in the limited classroom time. However, the students' learning process with the mobile devices is personalized. The learning content, interactions, and homework they choose can be recorded. Teachers can conduct formative evaluations to obtain a comprehensive understanding of each student, by which they can teach students in accordance with their aptitude. For example, some students have slow progress due to absence from class or other reasons, or not completing learning tasks in class. Teachers can use Podcast Technology to record the lecture content and send it to the students. Students can also use podcasts to give the feedback to teachers. This kind of interaction out of class enhances the understanding between teachers and students, so that teachers can truly realize quality-oriented education on the basis of respecting each student's personality and aptitude.

It can be seen that mobile technology-assisted language learning has unparalleled advantages in terms of extending learning time, enriching learning interaction, and improving learning efficiency (Hu Chajuan \& Zhang Yingchun, 2014) [12]. We should use mobile technology to connect the inside and outside of the 
class, so that students have more opportunities to be exposed to English.

\section{Implementation Steps of College English Teaching Mode Supported by Mobile Technology}

\subsection{Pre-Class Preparation Stage-Teachers Create Situations to Stimulate Student's Interest in Learning}

The pre-class learning in this mode makes full use of the convenience of M-learning, so that students can frequently get access to the information related to the content of the classroom learning on the stage of previewing. Through the stage teachers can know more students and thus teach students in accordance with their aptitude in the classroom learning stage. At the same time, students take the initiative to learn the content so that they can lay a foundation for the later classroom learning. Roughly, each lesson has a fixed theme. Before the class, the teacher will send relevant background knowledge and cultural knowledge to the students, and create a relevant situation for students in advance. At this stage, audio or video materials are used as the main learning resources. Teachers will send the carefully-prepared multimedia contents to the students. Then students learn the materials independently and give feedback by answering test questions. When students have problems about the preview content or want to have a deeper understanding, they can communicate with teachers through mobile devices. The purpose of this stage is to lay the foundation for the following classroom learning. The degree of input and preview effect in this stage directly affects the effect of students study in the classroom learning stage.

There are no fixed requirements for the time of the pre-class preparation stage. Each student uses mobile devices to make full use of all available scattered time to learn according to their own circumstance. The interaction between teachers and students can be realized real-time or non-real-time communication under this way.

\subsection{In-Class Learning Stage-Students Master the Knowledge and Language Skills through Experiencing Situations}

In classroom teaching, it is necessary to break the traditional purely-teaching method through the integration of multimedia technology and mobile technology with English, thus to change the presentation of teaching content, teaching methods and learning interaction methods. With the help of powerful information technology cognitive tools and rich learning resources it can promote the development of students' ability to solve complex problems in a real context and progress their overall performance, therefore improving the effectiveness of the English teaching in the classroom. Teachers guide students to use mobile devices such as mobile phones and audio players to conduct self-study at the right time. When the feedback is needed, they can use mobile phone to send the text messages to manage the real-time classroom teaching or adjust teaching in time. Students can also use mobile devices to check information when it is necessary. During the classroom teaching stage, teachers should adopt scaffolding teaching 
strategies, gradually transit the role from lecturers to instructors, monitors, etc., and more importantly transfer the main body of classroom learning to students, so that they can learn the English language meaningfully. At this stage, there are not only learning methods of transferring and receiving, but also the independent learning or cooperative learning among students.

\subsection{Expansion after Class-Students Interpret Situations and Improve Language Communication Skills}

Through organized learning in the classroom, students have gained a certain degree of cognition and practice of language in this unit, and have a deeper understanding of English language in combination with cultural background. In classroom teaching, the teachers also train listening and speaking strategies because most students have difficulty in listening and speaking. It can be said that after pre-class preview and classroom study, students have basically formed the cognition of the unit content, and have improved the accuracy of listening and the proficiency of spoken English. But this is not the end of the content of learning. The purpose of learning in one language is to use it in the real life. Therefore, after class, teachers should design task scenarios or assign communication tasks that need to be completed in cooperation to help students use English in their everyday life (Xiong Si \& Xiong Liangyun, 2012) [13].

\subsection{Evaluation System-Combine Formative Evaluation and Summative Evaluation}

Aiming at the problem in the traditional teaching model like "emphasizing summative evaluation and neglecting formative evaluation", the author of this article established a systematic evaluation system that combines formative evaluation and summative evaluation in the College English teaching model supported by mobile technology. The evaluation system focuses on the supervision of the process of pre-class self-learning, in-class interaction, and after-class practice demonstration (Liao Hongjian, 2014) [14]. The evaluation system consists of two parts: formative evaluation and summative evaluation, each with its own proportion. Among them, the summative evaluation is carried out at the end of the term, and the teacher will evaluate each student through formal and organized English test (Liao Hongjian, 2014) [14]. Formative evaluation system evaluates the performance of each student in and outside class, including the student's attendance, participation, homework or projects after the class, etc.. (Liao Hongjian, 2014) [14] The teacher uses various evaluation scales, which are obtained after quantification fraction.

The implementation of formative evaluation in the process of College English teaching can not only encourage students to reflect on their own learning process and adjust their learning plan, but also encourage teachers to reflect on their teaching process and adjust their teaching plans, so that both parties can better realize the virtuous circle of teaching and learning. Table 1 shows the main steps. 
Table 1. The steps of implementation of college English teaching supported by mobile technology.

\begin{tabular}{cccc}
\hline Step 1: Pre-class Stage & Step 2: In-class Stage & Step 3: After-class Stage & Step 4: Evaluation Stage \\
\hline & T-S interaction; Create & $\begin{array}{c}\text { Finish communication } \\
\text { tasks like scenarios or role }\end{array}$ & $\begin{array}{c}\text { Combine formative } \\
\text { evaluation with }\end{array}$ \\
$\begin{array}{c}\text { Preview the in-class } \\
\text { materials on mobile } \\
\text { devices. }\end{array}$ & $\begin{array}{c}\text { cooperative English } \\
\text { learning environment } \\
\text { through various Apps. }\end{array}$ & $\begin{array}{c}\text { play to further learning } \\
\text { with the use of mobile }\end{array}$ & $\begin{array}{c}\text { summative evaluation } \\
\text { with the aid of mobile }\end{array}$ \\
& & devices. & Apps. \\
\hline
\end{tabular}

\section{Conclusion}

With the development of wireless network technology, the function of mobile devices is becoming more and more perfect, so it is entirely possible to expand classroom teaching in English M-learning, to effectively link the in-class and after-class learning, formal learning and informal learning and create a relatively perfect English learning environment. Therefore, mobile devices can not only become English learning assistant, but also make a fundamental change in English teaching methods. As a new teaching method, research skills on the Mobile Leanning are still in its infancy, and the research in many places is still inadequate. Therefore, there will still be many follow-up studies for a long time in the future that we need to make further efforts to improve.

\section{Conflicts of Interest}

The author declares no conflicts of interest regarding the publication of this paper.

\section{References}

[1] Wang, S. (2009) Report on the Development of Foreign Language Education in Universities and Colleges (1978-2008). Shanghai Foreign Language Education Press, Shanghai.

[2] Cao, C. (2010) Use Podcasting Technology to Build a Mobile Learning Model for English Listening and Speaking. China Audio-Visual Education, 9, 99-103.

[3] Hu, J. and Chen, J. (2013) An Outline of Foreign Language Educational Technology. Audio- visual Foreign Language Teaching, 2, 3-12.

[4] Xu, T. (2014) Design and Implementation of Classroom Group Cooperative Learning Supported by Mobile Technology. Ph.D. Thesis, Zhejiang Normal University Studies, Jinhua.

[5] Wang, L. (2015) Design and Application Research of Exploring Learning Activities Supported by Mobile Technology. Ph.D. Thesis, Zhejiang Normal University Studies, Jinhua.

[6] Zhu, L. (2015) A Case Study of Probing and Ingenious Teaching of Elementary School Mathematics in a Mobile Environment. Ph.D. Thesis, Central China Normal University, Wuhan.

[7] Chen, H. (2013) Research on the Hybrid Teaching Mode of High School Chemistry Experiment Supported by Mobile Technology-Illustrated by D School in Changchun. Ph.D. Thesis, Yanbian University, Changchun.

[8] Jing, R. (2002) On the Teaching of English Listening and Speaking Courses Using 
Multimedia Technology. Journal of Liaoning Teachers College (Social Science Edition), 2, 102-103.

[9] Lan, L. (2006) Skillful Use of Multimedia Technology to Improve Students' English Listening and Speaking Ability. Journal of Changchun University, 12, 154-156.

[10] Lehner, F. and Nosekahel, H. (2010) Wireless E-learning and Communication Environment: Welcome at the University of Regenburg.

https://citeseerx.ist.psu.edu/viewdoc/download?doi=10.1.1.10.9268\&rep=rep1\&type $=\mathrm{pdf}$

[11] Liu, H. (2013) Investigation and Research on the Application of Apple Mobile Devices to Language Learning. Open Education Research, 1, 102-107.

[12] Hu, C. and Zhang, Y. (2014) Construction of College English Writing Feedback Model Based on Mobile Learning Analysis of construction factors. Modern Educational Technology, 7, 71-78.

[13] Xiong, S. and Xiong, L. (2012) Research and Design of Mobile Learning Mode in Higher Education. Journal of Hubei Second Normal University, 8, 21-24.

[14] Liao, H. (2014) Location-Based Personal Knowledge Map and Its Application in Mobile Learning. Audio-Visual Education Research, 6, 96-103. 